9.

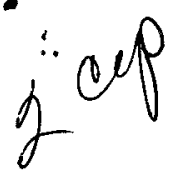

\title{
IN-PHANTOM DOSIMETRY OF PROTOTYPIC PLUTONIUM \\ CIRCULATORY SUPPORT HEAT SOURCES*
}

F. T. Cross and J. C. Sheppard

Battelle

Pacific Northwest Laboratories

Richland, washington 99352

February 1972

*This paper is based on work performed under U. S. Atomic Energy Commission Contract AT(45-1)-1830. sponsored by the United States Government. Neither the United States nor the United States Atomic Energy Commission, nor any of their employees, nor any of their contractors, subcontractors, or their employees, makes any warranty, express or implied, or assumes any legal liability or responsibility for the accuracy, completeness or usefulness of any information, apparatus, product or process disclosed, or represents that its use would not infringe privately owned rights. 


\section{DISCLAIMER}

This report was prepared as an account of work sponsored by an agency of the United States Government. Neither the United States Government nor any agency Thereof, nor any of their employees, makes any warranty, express or implied, or assumes any legal liability or responsibility for the accuracy, completeness, or usefulness of any information, apparatus, product, or process disclosed, or represents that its use would not infringe privately owned rights. Reference herein to any specific commercial product, process, or service by trade name, trademark, manufacturer, or otherwise does not necessarily constitute or imply its endorsement, recommendation, or favoring by the United States Government or any agency thereof. The views and opinions of authors expressed herein do not necessarily state or reflect those of the United States Government or any agency thereof. 


\section{DISCLAIMER}

Portions of this document may be illegible in electronic image products. Images are produced from the best available original document. 


\section{IN-PHANTOM DOSIMETRY OF PROTOTYPIC PLUTONIUM}

CIRCULATORY SUPPORT HEAT SOURCES

F. T. Cross and J. C. Sheppard

Battelle

Pacific Northwest Laboratories

Richland, Washington 99352

\section{Introduction}

Beginning in 1967 , Battelle-Northwest, under contract to the U. S. Atomic Energy Commission, initiated an in-phantom dosimetry program for characterizing, by measurement and computation, the tissue dose rates from radioisotopic heat sources suitable for use in a circulatory support system powered by a thermal engine. The first sources characterized were ${ }^{147} \mathrm{Pm}_{2} \mathrm{O}_{3}$ ' which contained about $44,000 \mathrm{Ci}$ of ${ }^{147} \mathrm{Pm}$ and produced about $15 \mathrm{~W}$ of thermal energy from the heat of their beta decay. [1] The conclusions were that ${ }^{146} \mathrm{Pm}$ impurity associated with the ${ }^{147} \mathrm{Pm}$ would need to be reduced at least an order of magnitude (to $<0.02 \mathrm{ppm}$ ) before the physical dose rates would be comparable to those from ${ }^{238} \mathrm{Pu}$. Even if this were done, however, the promethium source would be heavier since it has a lower power density, and because of its 2.6-year half-life compared 
with nearly 90 years for plutonium, the useful or mission life of promethium would be markedly less. The second source characterized was a $30 \mathrm{~W}$ plutonium metal source containing 80 wt\% ${ }^{238} \mathrm{Pu}\left(\sim 900 \mathrm{Ci}{ }^{238} \mathrm{Pu}\right), 0.58 \mathrm{ppm}{ }^{236} \mathrm{Pu}$ and negligible quantities of other contaminating isotopes insofar as their contribution to the tissue dose rates. [2] Currently, the dose rates from a $32 \mathrm{~W}$ medical grade ${ }^{238} \mathrm{PuO}_{2}{ }^{16}$ source contained in a prototypic artificial heart power source subsystem are being determined. This paper will be concerned with the dose rates from plutonium sources and, in particular, with those dose rates being determined for the medical grade oxide source contained in a prototypic Rankine power source subsystem.

\section{Plutonium Power Source Description}

The plutonium oxide source, the preferred fuel for high temperature applications, was fabricated at Los Alamos Scientific Laboratories. It contains about $87 \mathrm{wt} \%{ }^{238} \mathrm{pu}$ and 0.25 ppm ${ }^{236} \mathrm{pu}$. As for the metal source, other isotopic impurities do not significantly contribute to the tissue dose rates. The neutron emission rate of the oxide source is only slightly greater than that for an equivalent strength metal source and, of course, is due to the replacement of natural oxygen with ${ }^{16} \mathrm{O}$, an oxygen isotope of much lower $(\alpha, n)$ cross-section.

The plutonium oxide source was placed in a heat source system (the Rankine prototypic power source subsystem) fabricated at Hittman Associates, Inc. (P. O. Box 810, Columbia, Maryland 21043). This device was developed by Hittman 
Associates as part of an AEC contract to model heat source systems that were compatible with the Rankine and stirling technology developed by the AEC and the National Heart and Lung Institute. This device, diagrammed in Figure 1, in actuality contains the fuel capsule with Hastelloy-C and Ta-low containment, IiF/IiCl thermal energy storage material (TESM) and container, multifoil vacuum insulation and container, boiler tubes and seals for mating with a Rankine cycle thermal engine and finally, the outside containment which is about $10 \mathrm{~cm}$ diam. by $7.5 \mathrm{~cm}$ high. . If this device were part of the artificial heart power source, the overall height would be greater commensurate with the 1-2 liter projected volume for both the heat source and the thermal engine.

Experimental Design

our programmatic approach is to make measurements on various prototypic power sources placed in various tissueequivalent phantoms and then try to predict these measurements by developing or adapting suitable computer codes. The codes are then used in parametric studies and for the prediction of dose rates from sources not available for measurement. The prototypic power sources may be encapsulated sources only or encapsulated sources placed within portions of the circulatory support system hardware. Each step of progression toward an actual power source (heat source and thermal engine) makes the dosimetry more relevant.

The in-phantom dosimetry measurements are made within 
and surrounding two types of phantoms. One is a large homogeneous cylinder of $35 \mathrm{~cm}$ diam. $\times 50 \mathrm{~cm}$ height filled with tissue-equivalent fluid. The other is a Remab or heterogeneous man-simulating phantom containing a skeleton and lower density lung organ as well as various apertures for inserting dosimeters. Because the Remab phantom is of a shape and size of an average type inaividual, actually representative of the U. S. Air Force 50th percentile male, the measurements with this phantom are more representative of those for an artificial heart recipient of similar size and shape. The measurements in the larger homogeneous phantom more accurately reflect the change in source-dosimeter separation distance and for that reason are used in the comparison with the dose predictions. The photon dose rates are measured with small thermoluminescent dosimeters $(T L D-700), 0.125$ in. $\times 0.125$ in. $\times 0.035$ in., known to be insensitive to fission neutrons. The neutron dose rates are measured with tissue-equivalent proportional counters ranging in size from about $9 \mathrm{~cm}$ to about $0.6 \mathrm{~cm}$ in active diameter. The proportional counters consist of spheres of tissue-equivalent plastic surrounding a cavity filled with tissue-equivalent gas at a pressure chosen to simulate small 2- $\mu \mathrm{m}$ diameter tissue sites. Pulse height discrimination is used to reject gamma interference. Further information on the operation of the counters can be found in various chapters of the text books Radiation Dosimetry. [3] Because the neutron emission rate from a nominal $30 \mathrm{~W}{ }^{238} \mathrm{Pu}$ source is 1ow, suitably large ${ }^{252}$ Cf sources are used as a stand-in for most of the 
measurements. Both ${ }^{252} \mathrm{Cf}$ and medical.grade ${ }^{238} \mathrm{Pu}$ are fission sources with similar mean neutron energies, thus, it would be expected that if they are similarly contained, i.e., placed in the prototypic power sources, the only difference in their neutron dose rates would arise from their different neutroil emission rates. The measurements confirm this, and therefore most of the ${ }^{238} \mathrm{Pu}$ neutron dose rates are derived from the ${ }^{252} \mathrm{Cf}$ measurements. The intensities of the sources are determined with a long-counter in a relatively scatter-free environment. Because we are only interested in relative neutron emission rates, the measurements are subject to error cancellation and can be claimed to be no more than a few percent in error.

Computational Code and Input Data

Only a general description of the computational code will be presented as a much more detailed "User's Manual" is currently being written. The computer code QAD-P5A $[4,5]$ is being used for the dose rate calculations. QAD-P5A is a point-kernel code designed for computing photon and neutron dose rates from a volume-distributed radiation source. The shielding zones surrounding the source are defined in terms of intersecting planes and quadratic surfaces. A modified moments method is used for calculating the neutron dose rates. We have modified the code by enlarging its capacity to handle many more boundaries, zones, compositions, elements, energy groups and source-kernels in order to accommodate the projected circulatory support systems. In addition, the QAD library 
has been updated by incorporating the photon interaction coefficients of Storm and Israel[6] and the Bach-Caswell [7] neutron fluence-to-kerma factors. Some minor alterations of output format also have been made.

Dose Rate Computations and Measurements

The ${ }^{238} \mathrm{Pu}$ abundances of Lederer, Asaro and Perlman ${ }^{[8]}$ were used to calculate the photon dose rates from the prototypic sources placed centrally in a large homogeneous tissue phantom. Due to source self-absorption and shielding by the source containment, most of the photons below about $200 \mathrm{keV}$ in energy do not significantly contribute to the tissue dose rates. In fact, the majority of the photon dose results from the absorption of the ${ }^{238} \mathrm{Pu} 766 \mathrm{keV}$ gamma. Because a photon experiences scattering in more than one material, an effective atomic number material must be selected for calculating the dose build-up. It was noted that the ${ }^{147} \mathrm{Pm}_{2} \mathrm{O}_{3}$ calculations converged upon the measurements if the buildup factors for iron were used in the first $8 \mathrm{~cm}$ of tissue and if the buildup factors for water were used thereafter. In the case of implanted ${ }^{238} \mathrm{Pu}$ capsules, i.e., sources not contained in any subsystem, the measurements were only poorly predicted if the buildup factors for water were used. Rather, the buildup factors for lead and iron yielded calculations in closer agreement with the measurements, at least in the first $20 \mathrm{~cm}$ or so of tissue. For the oxide source contained in the prototypic power source subsystem, we again find that the measurements are predicted 
fairly accurately with iron buildup factors, in this case for the first $25 \mathrm{~cm}$ source center-dosimeter distance, and with water buildup factors thereafter. The dosimetry calculations and the comparison with the measurements will appear in a final dosimetry report.

The photon dose rate measurements in the large homogenous phantom for an implanted Rankine prototypic power source subsystem containing a $32 \mathrm{~W}^{238} \mathrm{PuO}_{2}{ }^{16}$ source, fit the equations:

$$
\begin{aligned}
& D_{X+R}=\frac{690.7}{(X+R)^{2}} e^{-0.029765(X+R)} \begin{array}{c}
\text { Radial direction } \\
\text { (side) }
\end{array} \\
& D_{X+R}=\frac{589.9}{(X+R)^{2}} e^{-0.033405(X+R)} \quad \begin{array}{l}
\text { Axial direction } \\
\text { (top and bottom) }
\end{array}
\end{aligned}
$$

where $D_{X+R}$ is the dose rate in mrads/hr and $(X+R)$ is the source center-dosimeter distance. $\mathrm{x}$ is the tissue thickness and $\mathrm{R}$ is the device thickness measured from the source center. The R-values for the Rankine prototypic power source subsystem are $5.0,3.9$ and $3.5 \mathrm{~cm}$, respectively, for the side, top and bottom directions. Because the heat engine sits atop the power source subsystem, the tissue dose rates out the top will be lower than the equation predicts, however those dose rates out the side and the bottom are expected to apply to a typical power source system. The equations predict an average tissue absorption of $3.11 \% / \mathrm{cm}$, which is typical of a photon of energy near $0.8 \mathrm{MeV}$, corroborating the $\mathrm{QAD}$-code predictions that the majority of the photon dose rates can be attributed to the 
$766 \mathrm{keV}{ }^{238} \mathrm{Pu}$ gammas.

Similarly, the neutron dose rate measurements in the large homogeneous phantom appear to fit the equation:

$$
D_{X+R}=\frac{406.3}{(X+R)^{2}} e^{-0.121438(X+R)} \quad \begin{aligned}
& \text { Radial and Axial } \\
& \text { directions }
\end{aligned}
$$

It is apparent that the neutron interactions with the eutectic material inside the device are compensating for the varying material thicknesses and that for equal $(X+R)$, or total thickness, the neutron dose rates are the same. The equation predicts that the decrease in neutron dose rate is about $11.4 \% / \mathrm{cm}$ of tissue in addition to the inverse-square falloff:

Those measurements in the Remab phantom are shown in Figures 2,3 and 4 . In each case a quality factor of 10 was chosen for the neutron dose rates and the growing-in of the ${ }^{236} \mathrm{Pu}$ dose is neglected. The 10-year average dose rates, however, are only about 15\% greater than these initial values. Figure 2 shows some measurements on the surface of the Remab phantom. The dose rate in mrems/hr is approximately twice the physical dose rate (mrads/hr) for those locations near the source but because the neutron dose rates decrease more rapidly than the photon dose rates, the neutron contribution to the total dose is considerably less at the more distant locations. When the encapsulated ${ }^{238} \mathrm{Pu}$ metal source was implanted, the neutron contribution to the physical dose never exceeded about $15 \%$ and was more on the order of 18 at the distant locations. 
For the oxide source contained in the Rankine prototypic power source subsystem, the neutron contribution to the physical dose uid not exceed about $20 \%$ and was on the order of $5 \%$ at the more distant locations. This behavior can be attributed to the displacemen $=$ of tissue by the subsystem thereby increasing the neutron dose rates at identical distances from the source center. In addition, the photons experience a greater attenuation in the materials composing the subsystem than in tissue. By the same reasoning, a prototypic power source which contains the thermal engine would displace even more tissue causing the $\mathrm{n} / \mathrm{\gamma}$ ratio opposite the thermal engine to increase again. If necessary, the power source could be oriented in such a fashion to minimize the biological dose to particularly sensitive organs.

Figure 3 is similar to Figure 2 except that the surface dose rates are measured in the bisecting radial plane of the source and $1 \mathrm{ft}$. and $3 \mathrm{ft}$. from the body surfaces. Because the measurements are in the highest dose rate plane, the values represent the maximum likely to be found external to the Remab phantom.

Figure 4 shows the dose rates along the central axis of the Remab phantom. In this case most of the neutron dose rates were derived from the ${ }^{252} \mathrm{Cf}$ measurements in the homogeneous phantom. The dose locations are about $5-1 / 2 \mathrm{~cm}$ apart and do not necessarily pertain to the indicated organ locations. The regions of various organ systems are shown for reference only, however, those organs lying quite close to the central axis 
of the body and which are small in volume are expected to have similar dose rates. We are presently calculating the dose rates to various organs using the heterogeneous mathematical man described by Snyder, Fisher, Ford and Warner. [9] These calculations will also appear in the final dosimetry report.

\section{Integrated and Average Body Dose Rates}

In deriving these values, it was assumed that a $40-\mathrm{cm}-$ diam. sphere with a centrally placed source would approximate the artificial heart recipient. This size sphere contains a mass of tissue roughly equivalent to the standard elliptical cylinder trunk phantom which has minor and major axes of 20 and $36 \mathrm{~cm}$ and a height of 50 to $70 \mathrm{~cm}$. Also a spherical shape tends to maximize the integrated dose as any other shape would allow more of the radiations to escape to the outside of the body. It is further assumed that the power source package for the artificial heart is a sphere of 10-cm-diam., again an overestimation of the dose since the tissue excluded is about $1 / 2$ liter in volume compared with the 1 to 2 -liter projected size of the device. The choice of 10 for the quality factor also tends to maximize the dose rates. Now, for a $30 \mathrm{w}^{238} \mathrm{PuO}_{2}{ }^{16}$ source contained in a Rankine prototypic power device,

1. If the ${ }^{236} \mathrm{Pu}$ could be eliminated, the average dose rate over a 10-year mission life is $0.19 \mathrm{rem} /$ day or $69 \mathrm{rem} /$ year.

2. The $0.25 \mathrm{ppm}{ }^{236} \mathrm{pu}$ impurity increases the average dose rate to the "body" to $0.23 \mathrm{rem} /$ day or $82 \mathrm{rem} / \mathrm{year}$, an 
increase of $20 \%$.

3. The integrated dose for this prototypic power source is just above 800 remis for the 10 -year period and the irreducible minimum is about $700 \mathrm{rem}$, which is for a ${ }^{238} \mathrm{PuO}_{2}{ }^{16}$ source containing no impurities. These values are to be multiplied by 33,500 if gram-rems are desired. In the absence of ${ }^{236}$ Pu impurity, the 10-year integrated and average body dose rates for a $30 \mathrm{w}^{238} \mathrm{PuO}_{2}{ }^{16}$ source and a $30 \mathrm{~W}$ ${ }^{238} \mathrm{Pu}$ metal source are not significantly different. However, the smaller quantity of ${ }^{236}$ pu associated with the oxide source (0.25 ppm compared with $0.58 \mathrm{ppm}$ for the metal source) has resulted in a reduced integrated 10-year average dose rate. This value was previously determined to be $0.29 \mathrm{rem} /$ day for the metal source. What can be concluded from these numbers?

\section{Conclusions}

Various reviews of the radiobiological effects of implantable heat sources have appeared, perhaps the most extensive, and one resulting in general guidelines on a "safe" dose level for an implant recipient, was performed by Hittman Associates for the National Heart and Iung Institute. [10] This review and various animal studies completed and currently in progress seem to vindicate the use of plutonium heat sources in circulatory support systems (see e.g., Ref. [11] and mention should be made of Battelle-Northwest's current study on the radiobiological effects of $50 \mathrm{~W}{ }^{238} \mathrm{PuO}_{2}{ }^{16}$ sources in swine). Aside from the above, it is estimated that early radi- 
$-12-$

ologists may have received lifetime radiation exposures (reprated intermittent partial body) as high as a few thousand roentgens, and that the body might tolerate exposure rates greater than IR/day for a period of years. [12] Such considertrons lead one to guess that, dependent on the circumstances, such as recipient age, etc., acceptable dose rates might be placed either below or above $100 \mathrm{rem} /$ year. A circulatory support system incorporating a heat source, therefore, is probably acceptable from a radiation dose standpoint independent of its acceptability as a prosthetic device. 


\section{$\underline{\text { References }}$}

[1] F. T. Cross and J. C. Sheppard, In-Phantom Dosimetry of ${ }^{147} \mathrm{Pm}_{2} \mathrm{O}_{3}$ Heat Sources in Relation to Circulatory support Systems, Isotop. Radiat. Technol. 7 (1969) 231.

[2] F. T. Cross and J. C. Sheppard, In-Phantom Dosimetry of Plutonium-238 Circulatory Support Heat Sources, Nuclear Technology 13 (1972) 83.

[3] F. H. Attix, W. C. Roesch and E. Tochilin, Radiation Dosimetry, Academic Press, New York (1968).

[4] R. E. Malenfant, QAD: A Series of Point-Kernel General Purpose Shielding Programs, LA-3573, Los Alamos Scientific Laboratory (1967).

[5] G. P. Lahti, QADHD, A Point-Kernel Radiation Shielding Computer Code to Evaluate Propellant Heating and Dose to Crew During Engine Operation, NASA-TM-X 1397, National Aeronautics and Space Administration (1967).

[6] E. Storm and H. I. Israel, Photon Cross Sections from 0.001 to $100 \mathrm{MeV}$ for Elements 1 through 100, LA-3753, Los Alamos Scientific Laboratory (1967).

[7] R. I. Bach and R. S. Caswell, Energy Transfer to Matter by Neutrons, Radiat. Res., 35 (1968) 1 .

[8] C. M. Lederer, F. Asaro and I. Perlman, The Nuclear Properties of the Heavy Elements, UCRL-18667, University of California, Berkeley (1969).

[9] W. S. Snyder, H. L. Fisher, M. R. Ford and G. C. Warner, Estimates of Absorbed Fractions for Monoenergetic Photon 


\section{References (Continued)}

Sources Uniformly Distributed in Various organs of a Heterogeneous Phantom, MIRD Pamphlet No. 5, J. Nucl. Med. 10: Supplement 3 (1969).

[10] Radiation and Risk Analysis of Radioisotope Power Sources for the Artificial Heart Program, HIT-266, Hittman Associates, Inc., Baltimore, Maryland (1967).

[11] F. N. Huffman and J. C. Norman, Thermal and Radiation Effects of ${ }^{238}$ Pu Fuel Capsules on Dogs and Primates, Trans. Am. Nucl. Soc., No. 2, 14 (1971) 510.

[12] Exposure to Radiation in an Emergency, Report 29, National Committee on Radiation Protection and Measurements, Washington, D. C. (1962). 


\section{$-15-$}

\section{Figures}

Figure 1. Schematic of P:ototypic Power Source Subsystem.

Figure 2. Total $(n+\gamma)$ Dose-Rates in MREMS/HR on Surface of Remab Phantom.

Figure 3. Total $(n+\gamma)$ Dose-Rates in MREMS/HR in Bisecting Radial Plane of Source.

Figure 4. Total $(n+\gamma)$ Dose-Rates in MREMS/HR Along Central Axis of Remab Phantom. 


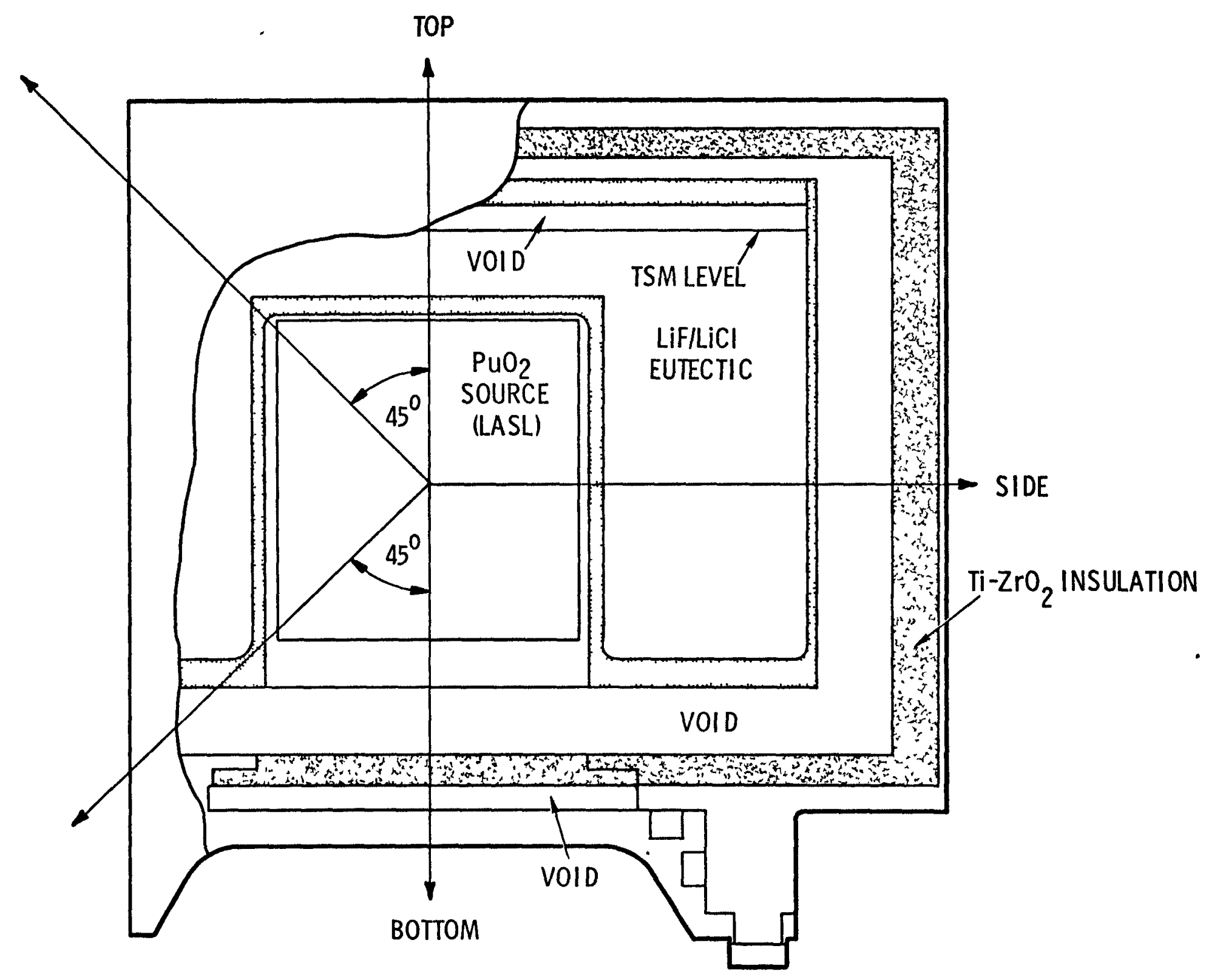

FIGURE 1. SCHEMATIC OF PROTOTYPIC POWER SOURCE SUBSYSTEM 


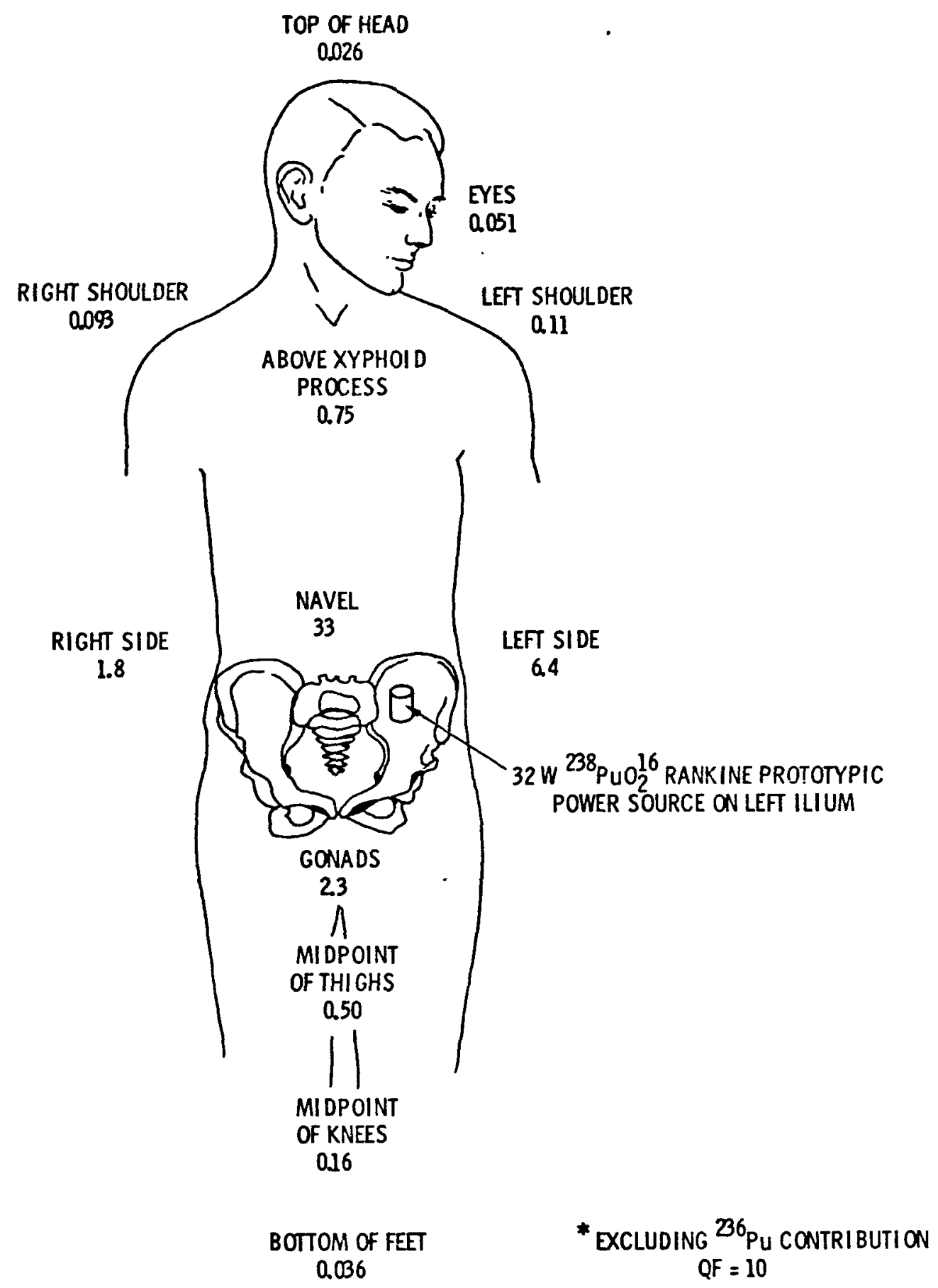

FIGURE 2. TOTAL $(n+\gamma)$ DOSE-RATES IN MREMS/HR ON SURFACE OF REMAB PHANTOM* 


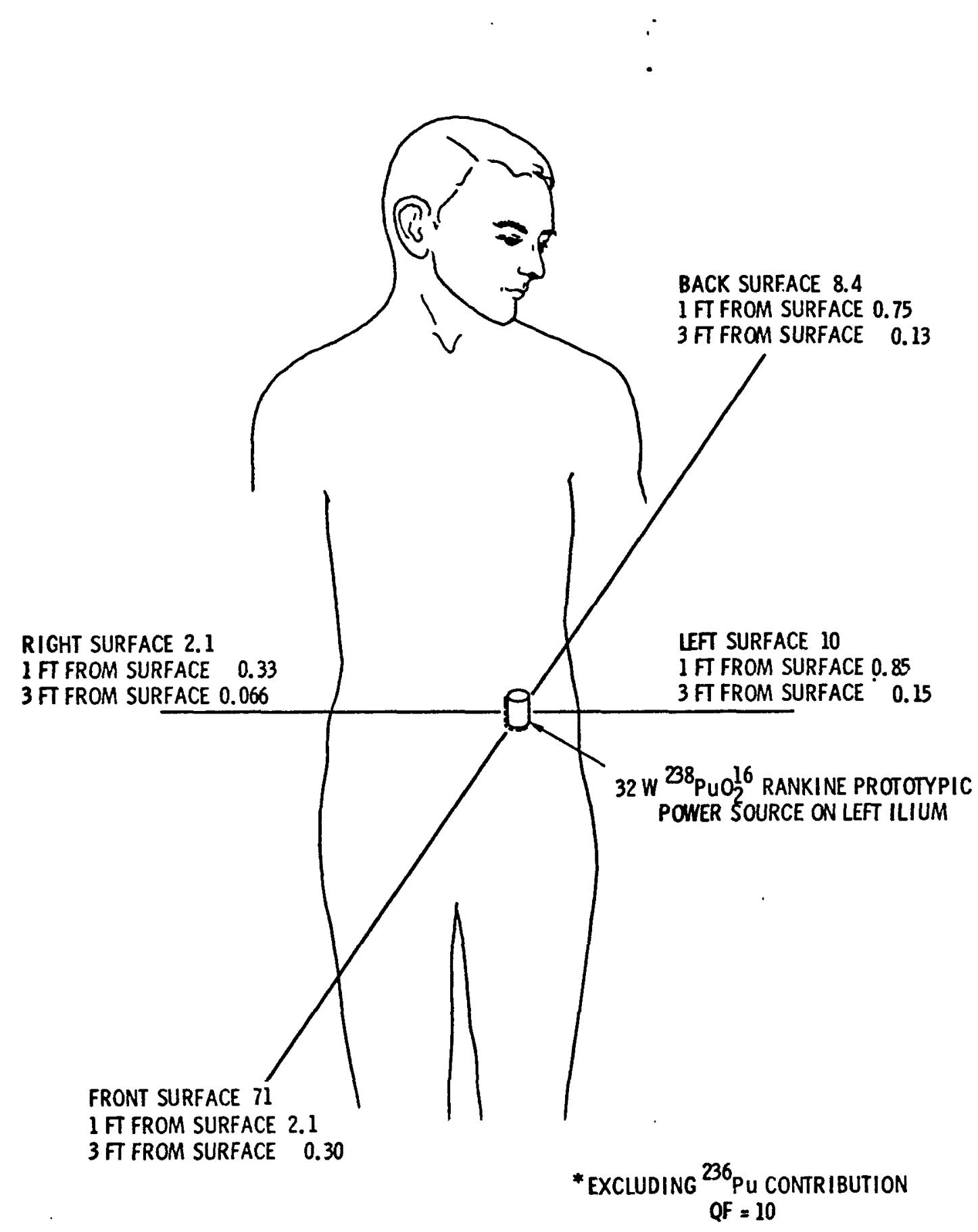

FIGURE 3. TOTAL $(n+\gamma)$ DOSE-RATES IN MREMS/HR IN BISECTING RADIAL PLANE OF SOURCE* 


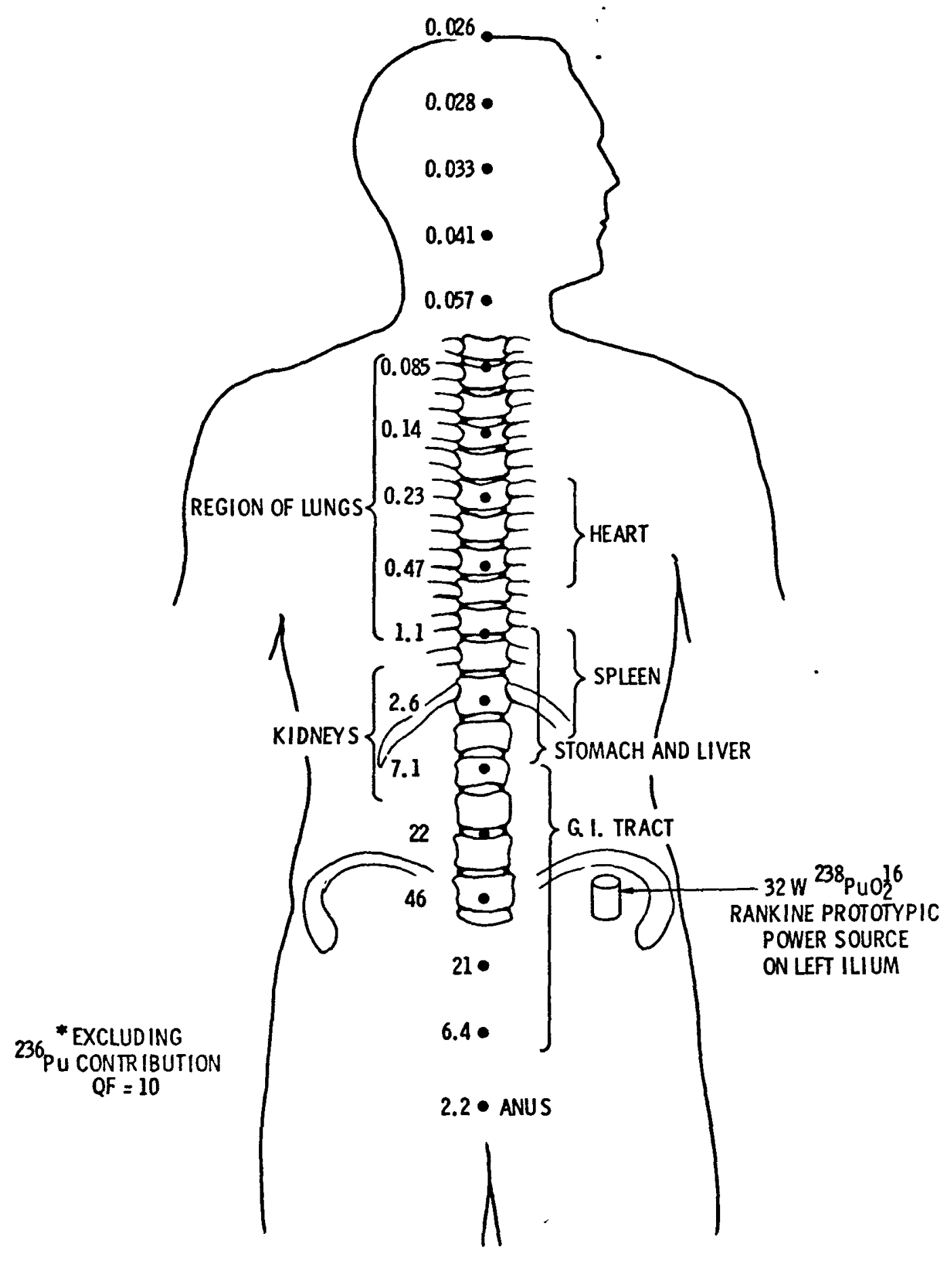

FIGURE 4. TOTAL $(n+\gamma)$ DOSE-RATES IN MREMS/HR ALONG CENTRAL AXIS OF REMAB PHANTOM* 